\title{
Towards Entrepreneurial Universities: Barriers, Facilitators, and Best Practices in Bulgarian and Portuguese Universities
}

\author{
Submitted 11/08/19, $1^{\text {st }}$ revision 10/09/19, $2^{\text {nd }}$ revision 23/10/19, Accepted 18/11/19
}

\section{Desislava Yordanova $^{1}$, José António Filipe ${ }^{2}$}

\begin{abstract}
:
Purpose: The main objective of this research is to investigate barriers, facilitators and best practices in the transformation of Bulgarian and Portuguese universities into entrepreneurial universities.

Design/Methodology/Approach: This study relies on a survey among experts in the field to identify barriers, facilitators and best practices in the transformation of Bulgarian and Portuguese universities into entrepreneurial universities.

Findings: The research findings demonstrate that there are both internal and external barriers and facilitators of the entrepreneurial transformation of universities in Bulgaria and Portugal and reveals the relative importance of the various internal and external factors. The study describes several best practices in the transformation towards an entrepreneurial university adopted at Sofia University "St. Kliment Ohridski" and ISCTE-IUL.

Practical Implications: This research raises awareness of the internal challenges to making Bulgarian and Portuguese universities more entrepreneurial as well as of factors that may facilitate the process of transformation and the need to strengthen entrepreneurship ecosystem at these universities. Policy makers should devote special attention to external barriers to the transformation and especially to the need for more appropriate legal framework and more state funding.
\end{abstract}

Originality/Value: The study highlights that the relative importance of the various internal and external factors is context specific.

Keywords: Entrepreneurial universities, barriers, facilitators, Bulgaria, Portugal.

JEL Codes: M19.

Article Type: Research paper.

Acknowledgements:

The research was supported by the Scientific Research Fund of Sofia University "St. Kliment Ohridski" (contract N 80-10-113/15.04.2019).

${ }^{1}$ Full Professor, Faculty of Economics and Business Administration, Sofia University "St. Kliment Ohridski"1113 Sofia, E-mail: d_yordanova@abv.bg

${ }^{2}$ Assistant Professor with Habilitation, ISCTE-Lisbon University Institute - ISCTE-IUL, Lisbon, Portugal; Information Sciences, Technologies and Architecture Research Center (ISTAR-IUL); Business Research Unit-IUL (BRU-IUL), E-mail: jose.filipe@iscte-iul.pt 


\section{Introduction}

The university underwent two academic revolutions, which brought significant changes in its mission and academic tasks (Etzkowitz, 2003). The first academic revolution led to the adoption of research as another university function in addition to the traditional academic task of teaching. The second academic revolution added a new academic task related to economic and social development and led to the emergence of the entrepreneurial university. Thus, in addition to teaching and research, the entrepreneurial university adopts a third mission for enhancing economic development (Etzkowitz et al., 2000). In an entrepreneurial society, where knowledge-based entrepreneurship is a driving source (Audretsch, 2009), the entrepreneurial university is both knowledge producer and a disseminating organization to the society (Guerrero et al., 2014). The emergence of the entrepreneurial university is a response to the increasing importance of knowledge in national and regional innovation systems (Etzkowitz et al., 2000).

Gibb et al. (2009) identify various environmental challenges fostering the transformation of universities into entrepreneurial organizations including the massification of higher education, employability agenda, globalization, students' voice, internationalization strategies in universities, the global knowledge configuration, regional and local engagement, etc. Our study defends that these factors contribute substantially to uncertainties and complexities in the environment of higher education institutions and demand entrepreneurial initiative by these institutions.

Previous empirical evidence suggests that Bulgarian and Portuguese universities experienced difficulties in the process of transformation into entrepreneurial universities. Bulgarian higher education institutions exhibit narrow understanding of the concept of innovative and entrepreneurial university (OECD, 2014). Entrepreneurship promotion is not a strategic goal for Bulgarian higher education institutions and they have rarely links with the entrepreneurial ecosystem in the country (OECD, 2014). Profound changes at all levels and across all systems in Bulgaria in the transition to market economy create opportunities for new systems to develop (Smith et al., 2000) including in the field of higher education.

Although a significant amount of students in Portuguese universities exhibit entrepreneurial propensity, their intentions are hindered by insufficient entrepreneurial preparation (Gerry et al., 2008). Portuguese academics are not very involved in entrepreneurial tasks compared to other academic activities (Sá et al., 2018). Moreover, Santiago et al. (2008) demonstrate that the idea of research as an entrepreneurial issue has not been completely institutionalized in Portuguese universities. Research on facilitators and barriers to the entrepreneurial transformation of universities is limited and there is a need for more research on this topic in different cultures and contexts (Kirby et al., 2011). 
The research aim of the present study is to investigate barriers, facilitators and best practices in the transformation of Bulgarian and Portuguese universities into entrepreneurial universities.

\section{Literature Review}

This section presents a literature review on the nature of entrepreneurial universities and stimulating factors and barriers to the transformation of universities into entrepreneurial ones. The concept of the "entrepreneurial university" was introduced by Etzkowitz (1983) and Clark (1983) (Nelles amd Vorley, 2010). Despite the increasing research interest in entrepreneurial university, there is still no agreement among researchers about the definition of this concept (Yusof and Jain, 2010). Universities may undertake entrepreneurial activities at various levels such as individual entrepreneurship, team entrepreneurial activities or institutional entrepreneurship (Fuller, 2005). Entrepreneurial activities within universities may include:

- $\quad$ spin-out and start-up of new ventures (Kirby, 2006; Zhou and Peng, 2008, p. 638);

- fund-generating activities like patents, licensing, research under by contracts and entry into a partnership with a private enterprise (Etzkowitz, 1983, p. 214; Jacob, Lundqvist and Hellsmark, 2003);

- commercialisation activities (e.g. custom made further education courses, consultancy services, extension activities) (Jacob, Lundqvist and Hellsmark, 2003);

- generation of technology advances (Rothaermel, Agung and Jiang, 2007);

- innovation in how the university goes to business (Clark, 1998).

Entrepreneurial activities within universities may be undertaken by various actors including faculty, students, employees (Röpke, 1998; Etzkowitz, 2003; Jacob, Lundqvist and Hellsmark, 2003), and the university itself (Clark, 1998; Röpke, 1998). Entrepreneurial universities exhibit several distinctive characteristics: entrepreneurial attitude (Rinne and Koivula, 2005), capability (Zhou and Peng, 2008), culture (Kirby, 2006), strong research (Zhou and Peng, 2008), closer university-business partnerships and greater responsibility for accessing external sources of funding (Subotzky, 1999; Etzkowitz, 1983), agility, flexibility, ability to change and adjust to external environment (Pawłowski, 2001; Barnett, 2005; Guerrero-Cano, Kirby and Urbano, 2006), ability to innovate, search, recognize and create opportunities and take risks (Clark, 1998; Guerrero-Cano, Kirby and Urbano, 2006; Pawłowski, 2001), implementation of management and business-like practices, organizational forms, and technologies (Subotzky, 1999; Ibarra-Colado, 2007). 
Entrepreneurial activities within entrepreneurial universities are supported by various support mechanisms, structures, and intermediaries such as technology transfer offices and the creation of incubators or science parks (Rothaermel, Agung and Jiang, 2007). In addition to direct mechanisms for supporting the transfer of technology from academia to industry there are also indirect mechanisms supporting entrepreneurial activities via entrepreneurship education (Guenther and Wagner, 2008).

The entrepreneurial university is involved in a transfer of technology from academia to industry (Guenther and Wagner, 2008) and facilitates the technology diffusion (Rothaermel, Agung and Jiang, 2007). Its numerous activities lead to a new demand for its products and create new clients (Pawłowski, 2001). There is a "structural coupling" between university and region (Röpke, 1998) which influences the regional development of industries as well as economic growth through high-tech entrepreneurship (Zhou and Peng, 2008).

Yusof and Jain (2010) identify six conceptual models of entrepreneurial university (Clark, 1998; Etzkowitz et al., 2000; Sporn, 2001; Etzkowitz, 2004; Kirby, 2006; Rothaermel et al., 2007). They argue that the available theoretical models of entrepreneurial university comprise a variety of elements that "should provide a basis for the identification of factors or antecedents which may determine or influence university-level entrepreneurial activities" (Yusof and Jain, 2010, p. 85). In this section we review the elements of the existing conceptual models of entrepreneurial university. Clark (1998) outlines five organizational elements that should be developed or changed in order a university to transform itself into an entrepreneurial one: strengthened steering core, expanded developmental periphery, diversified funding base, stimulated academic hearthland, and integrated entrepreneurial culture. Drawing upon various processes related to changes in the production, exchange and use of knowledge, Etzkowitz et al.'s (2000) model describes five developmental mechanisms and emergent structures of the entrepreneurial university. Internal transformation involves redefinition and expansion of traditional academic tasks. Trans-institutional impact may be created through institutionalization of formats for collaborative arrangements in order to achieve stabilization. Interface processes are associated with the development of various interface capabilities. Recursive effects are achieved as the university itself develops capabilities to support entrepreneurial activity.

Sporn (2001) argues that the entrepreneurial transformation and adaptive behaviour of universities may by hindered by bureaucratic and collegial university structures. Their case-study research demonstrates that universities may introduce new organizational forms such as specific organizational culture, networks, strategic alliances and mergers, and conglomerates to adapt to changes in the external environment. In response to environmental forces and increasing globalisation and international competition, universities try to achieve greater flexibility, efficiency and effectiveness through changes in their governance, management and leadership 
structures. Sporn (2001) identifies the following critical factors for the adaptation and entrepreneurial transformation of universities: clear mission statement and goals; entrepreneurial culture; differentiated structure; professionalization of university management; shared governance; and committed leadership.

Etzkowitz (2004) formulates five norms of the entrepreneurial university derived from the development of entrepreneurial universities in various contexts: capitalization of knowledge; interdependence with industry and government; independence from other institutional spheres; creation of hybrid organizational forms; and reflexivity involving continuous renovation of internal structures of the university.

Kirby's (2006) model describes specific actions for the development of an entrepreneurial university such as endorsement, incorporation, implementation, communication, encouragement and support, recognition and reward, organization, and promotion.

The "entrepreneurial university" is placed in the center of Rothaermel et al.'s (2007) conceptual framework of university entrepreneurship. They stress that entrepreneurial university generates and facilitates the commercialization of new knowledge, technology diffusion processes and the creation of new firms. Technology transfer offices and other university structures such as incubators and science parks are important part of the overall university innovation system acting as intermediaries in the technology diffusion process. The authors conclude that entrepreneurial universities are embedded in various networks of innovation pertaining to the external environmental context.

We identified two recent conceptual models by Kirby et al. (2011) and Guerrero and Urbano (2012). Drawing upon Institutional Economics, Kirby et al. (2011) propose a conceptual framework of entrepreneurial universities formal and informal factors that facilitate the development of entrepreneurial universities. Formal facilitators include entrepreneurship courses for students and academics, support for technology transfer, support measures for start-ups, links with industry, incubators and science parks, flexible organizational and governance structure. Informal facilitators include favourable student attitudes, favourable academic attitudes, entrepreneurship role models, adequate cultural values, appropriate reward system, ways of teaching.

In Guerrero and Urbano's (2012) model, the outcomes of entrepreneurial universities are a function of formal and informal environmental factors and internal resources and capabilities. Guerrero et al. (2014) adapt and extend Guerrero and Urbano's (2012) model to show the link between these factors and universities' outcomes (teaching, research and entrepreneurial activities) and their impact on economic and social outputs. 
Empirical research on entrepreneurial university has investigated barriers to universities becoming more entrepreneurial and internal and external factors for the development of entrepreneurial university (Rothaermel et al., 2007; Markuerkiaga et al., 2014). Empirical findings highlights diverse factors influencing entrepreneurial university including legislation (Grimaldi et al., 2011; Aldridge and Audretsch, 2011), expectations of the society, industry, government and market (Salamzadeh et al., 2011), local-context support mechanisms (Fini et al., 2011), entrepreneurial mission, entrepreneurial organization and governance structure, entrepreneurship education programs (Guerrero et al., 2011; Salamzadeh et al., 2011; Kirby et al., 2011), favourable staff attitudes toward entrepreneurship (Kirby et al., 2011), funding (O'Shea et al., 2005; Powers and McDougall, 2005; Hu, 2009; Lehrer et al., 2009), individual incentives for entrepreneurial behaviour (Henrekson and Rosenberg, 2001), changes in infrastructure and culture (Jacob et al., 2003), infrastructure support measures (science parks, incubators, technology transfer offices) (Gras et al., 2008; Coupe, 2003; Clarysse et al., 2011; Van Looy et al., 2011; Etzkowitz, 2003; Guerrero et al., 2011; Kirby et al., 2011), non-economic support measures such as training advice (Gras et al., 2008), social environment (Clarysse et al., 2011), human capital and organizational resources (Powers and McDougall, 2005).

Empirical research reveals various barriers to universities becoming more entrepreneurial. Drawing upon a survey among experts, Kirby et al. (2011) identify several major barriers to the development of entrepreneurial universities: organizational structure and university governance, inadequate links with the industry, not in concordance with research objectives, lack of experience, inadequate cultural values, traditional ways of teaching, inappropriate reward systems, clash with teaching objectives, lack of funding, lack of physical resources, and state funding/ dependency on the state. Philpott et al. (2011) provide evidence of major institutional barriers including academic progression processes, lack of entrepreneurial role models, and absence of a unified entrepreneurial culture.

The only empirical study on barriers and facilitators to the success of entrepreneurial universities based on a survey among experts was conducted by Kirby et al. (2011). Kirby et al. (2011) note that their findings may be influenced by unique cultural, social and political factors related to the research context (Spain) and highlight the need to assess the generalization of their research findings across cultures and national boundaries.

\section{Research Methodology}

Following Kirby et al. (2011), this study relies on a survey among experts in the field to identify barriers, facilitators and best practices in the transformation of Bulgarian and Portuguese universities in to entrepreneurial universities. In Portugal, 5 experts ( 1 woman and 4 men) were identified in advance and invited to participate in the study. A survey among 23 Bulgarian experts (16 women and 7 men) was 
conducted between April and July, 2017. Some of the experts were attendees at the international scientific conference "Development of the Higher Schools in the Context of the European Requirements for Quality of Education Services", which was organized by the International Business School on 16-17 June 2017 in Sofia. The rest of the experts were identified in advance and invited to participate in the survey. Table 1 lists the types of experts included in the survey. The experts were asked to indicate the position(s) they currently hold or positions held in the past.

Table 1. Types of experts included in the surveys.

\begin{tabular}{|l|c|c|}
\hline \multicolumn{1}{|c|}{ Types of experts } & Bulgaria* $^{*}$ & Portugal \\
\hline Senior university administrator / university unit head & 9 & 5 \\
\hline $\begin{array}{l}\text { Senior administrator / expert in government institutions } \\
\text { in the field of education }\end{array}$ & 5 & 0 \\
\hline $\begin{array}{l}\text { Senior administrator / expert in the field of education in } \\
\text { NGO }\end{array}$ & 3 & 0 \\
\hline $\begin{array}{l}\text { Researcher in the field of management of higher } \\
\text { education, entrepreneurial universities }\end{array}$ & 14 & 0 \\
\hline
\end{tabular}

Note: * Some respondents have provided more than one answer.

The questionnaire used in the study includes questions, which requested a broad array of information related to demographic characteristics of respondents, position held, perceptions about the most significant facilitators and barriers to the transformation of Bulgarian universities into entrepreneurial ones as well as best practices adopted by Bulgarian universities. The next section describes the most frequently mentioned facilitators and barriers to the transformation of Bulgarian and Portuguese universities into entrepreneurial ones. Several best practices in the transformation towards an entrepreneurial university are identified at Sofia University "St. Kliment Ohridski” and ISCTE-IUL.

Sofia University "St. Kliment Ohridski" is the leading national centre for higher education and scientific research. The University offers majors at all three levels of education and manages the most advanced research in the fields of the social studies and humanities, as well as in the field of the natural sciences and mathematics. The University comprises sixteen faculties, three teaching centres and numerous research centres and laboratories. The overall number of students is more than 19000. International relations have a special place in the University`s global strategy as they considerably stimulate research and support, and improve the quality of teaching. Sofia University has contracts with more than 80 universities of different countries, thus facilitating a wide variety of joint international projects and multilateral professional contacts.

ISCTE-IUL is one of the most prestigious Portuguese universities offering an exceptional variety of programmes, covering a wide range of study areas in all cycles of higher education. Some of these study cycles are taught in English and others created in association with foreign partner universities, conferring a joint 
degree. ISCTE-IUL students have the possibility of completing part of their studies in one of the 450 foreign universities with which ISCTE-IUL has partnership agreements, while still benefiting from the competitive level of tuition fees in Portugal.

\section{Empirical Findings}

Table 2 reveals the facilitators contributing to making Bulgarian universities more entrepreneurial. They are rank ordered according to their frequency in the answers provided by experts. Increasing links between universities and business is the most important facilitator. Other facilitators include requirements and expectations of current and potential students, appropriate rewards for academic and administrative staff, entrepreneurship education, favourable conditions for entrepreneurship development within the university, training for academic and administrative staff, greater funding, investment in equipment and technologies, more academic courses with practical orientation, competition between universities, inclusion of students in the transformation process.

Table 2. Facilitators to the transformation of Bulgarian universities into entrepreneurial ones.

\begin{tabular}{|l|c|}
\hline \multicolumn{1}{|c|}{ Facilitator } & Rank \\
\hline Increasing links between universities and business & 1 \\
\hline Requirements and expectations of current and potential students & 2 \\
\hline Appropriate rewards for academic and administrative staff & 3 \\
\hline Entrepreneurship education & 4 \\
\hline Favourable conditions for entrepreneurship development within the university & 5 \\
\hline Training of academic and administrative staff & 6 \\
\hline Funding & 7 \\
\hline Investment in equipment and technologies & 8 \\
\hline Increasing the number of academic courses with practical orientation & 9 \\
\hline Competition between universities & 9 \\
\hline Inclusion of students in the transformation process & 9 \\
\hline
\end{tabular}

Table 3 reveals that the most frequently mentioned facilitators to the transformation of Portuguese universities are leadership and strategic vision and motivated and dedicated staff. Other facilitators include favourable conditions for entrepreneurship development within the university, appropriate rewards for academic and administrative staff, funding, and the participation into international networks of entrepreneurial universities.

The rank order of factors identified by experts as barriers to the transformation of Bulgarian universities into entrepreneurial universities is presented in Table 4. The most important barrier is the lack of appropriate organizational structure and governance in Bulgarian universities. Other frequently mentioned barriers are the lack of appropriate legislation, lack of links with business, lack of strategic vision, 
lack of entrepreneurial culture, lack of resources, lack of appropriate rewards, lack of funding, lack of experience.

Table 3. Facilitators to the transformation of Portuguese universities into entrepreneurial ones.

\begin{tabular}{|l|c|}
\hline \multicolumn{1}{|c|}{ Facilitator } & Rank \\
\hline Leadership and strategic vision & 1 \\
\hline Motivated and dedicated staff & 1 \\
\hline Favourable conditions for entrepreneurship development within the university & 2 \\
\hline Appropriate rewards for academic and administrative staff & 2 \\
\hline Funding & 2 \\
\hline Participation into international networks of entrepreneurial universities & 2 \\
\hline
\end{tabular}

Table 4. Barriers to the transformation of Bulgarian universities into entrepreneurial ones.

\begin{tabular}{|l|c|}
\hline \multicolumn{1}{|c|}{ Barrier } & Rank \\
\hline Lack of appropriate organizational structure and governance & 1 \\
\hline Lack of appropriate legislation & 2 \\
\hline Lack of links with business & 3 \\
\hline Lack of strategic vision & 4 \\
\hline Lack of entrepreneurial culture & 5 \\
\hline Lack of resources & 6 \\
\hline Lack of appropriate rewards & 7 \\
\hline Lack of funding & 8 \\
\hline Lack of experience & 9 \\
\hline Lack of adequate entrepreneurship support infrastructure & 10 \\
\hline Inadequate teaching methods and content of academic disciplines & 10 \\
\hline Aging academic staff & 10 \\
\hline Low internationalization of higher education institutions & 10 \\
\hline Lack of entrepreneurial skills of academic staff & 10 \\
\hline Lack of interest from students & 10 \\
\hline Narrow specialization & 10 \\
\hline
\end{tabular}

Table 5 presents the rank order of factors identified by experts as barriers to the transformation of Portuguese universities into entrepreneurial universities. The most important barrier is the mentality/mindset of academic and administrative staff. Similarly to Bulgarian universities, the lack of appropriate organizational structure and governance in Portuguese universities seems to be a major barrier to their transformation into entrepreneurial universities. Other frequently mentioned barriers are the lack of funding, existing organizational culture in Portuguese universities, lack of appropriate rewards, lack of mentors, lack of entrepreneurial intentions, lack of understanding in the community on the need and benefit on being an entrepreneurial university and need to improve/ deepen links with business. 
Table 5. Barriers to the transformation of Portuguese universities into entrepreneurial ones.

\begin{tabular}{|l|c|}
\hline \multicolumn{1}{|c|}{ Barrier } & Rank \\
\hline Mentality/mindset & 1 \\
\hline Lack of appropriate organizational structure and governance & 2 \\
\hline Lack of funding & 2 \\
\hline Existing organizational culture & 2 \\
\hline Lack of appropriate rewards & 2 \\
\hline Lack of mentors & 3 \\
\hline Lack of entrepreneurial intentions & 3 \\
\hline $\begin{array}{l}\text { Lack of understanding in the community on the need and benefit on being an } \\
\text { entrepreneurial university }\end{array}$ & 3 \\
\hline Need to improve/ deepen links with business & 3 \\
\hline
\end{tabular}

Several best practices in the transformation towards an entrepreneurial university adopted at Sofia University "St. Kliment Ohridski" and ISCTE-IUL have been identified. Entrepreneurship and innovation are core concerns of ISCTE-IUL. There are several observatories at ISCTE-IUL, which are independent structures connected to the research units, designed to support research about current subjects and pressing challenges facing contemporary societies. The observatories' teams critically tackle their focus areas, contributing to the advancement of scientific knowledge and transferring their knowledge to society. They also contribute to the definition of research methodologies, delineation and evaluation of public policy and analysis and consulting services. ISCTE-IUL has a large number of protocols and partnership agreements. Particularly, the ISCTE Business School (IBS) continually seeks to establish new partnerships and business academic strengthening and improving existing partnerships. For IBS, the proximity to business schools and the business community is essential to creating value for all stakeholders, and for society in General.

Research and development of theoretical tools with application to practical cases is one of the foci of IBS, so as to promote the development of individuals and organizations. The proximity to the business world is always one of the most distinctive brands and one of the central elements of the reputation of the ISCTE Business School. The involvement of the business community in the activities of the School - in the design of programs, the host of applied research projects on participation in conferences and seminars, among many other areas of collaboration - has been an element fundamental for an intense and continuous connection between the school and business reality. In this respect, it is also important to recognize the financing of several companies to the Management Excellence Programme, which assigns, annually, awards and incentives to the best students of the ISCTE Business School, in their different courses.

The Faculty of Economics and Business Administration (FEBA) is actively involved in various initiatives stimulating the transformation of Sofia University "St. Kliment 
Ohridski" into an entrepreneurial university. The career center at the Faculty of Economics and Business Administration and Center for Entrepreneurship and Project Management of Sofia University "St. Kliment Ohridski" organise annually a student competition for the best course work with entrepreneurial potential. The aim of competition is to stimulate and award the entrepreneurial and innovation potential and actions of the students through practical course works, developed within the studied disciplines. The main sponsors of the event and the members of the jury are representatives of the FEBA's partners from the business community. Students with the best course works receive financial support for the realization of their projects or mentoring from FEBA's business partners.

The FEBA offers an open academic course on entrepreneurship and innovation to encourage and support entrepreneurship among bachelor, master, and doctoral students from all faculties of the university as well as academic and administrative staff of the University. The course content includes the following topics:

- Introduction to entrepreneurship: definition, nature and importance.

- The figure of the entrepreneur. The entrepreneurial team.

- Identification of entrepreneurial opportunities. The business idea.

- The business model. The business Plan.

- The Entrepreneurial process.

- Innovation Management.

- Development of the new business.

- Competitiveness of the new business.

\section{Discussion and Conclusions}

The empirical findings of the present study reveal that both internal and external factors are seen by the participating experts as important facilitators of the transformation of Bulgarian and Portuguese universities into entrepreneurial ones. Our findings of the facilitators of entrepreneurial universities are consistent with the existing theoretical and empirical contributions (Rothaermel et al., 2007; Kirby et al., 2011). In Portugal leadership and strategic vision and motivated and dedicated staff are ranked as the most significant facilitators of entrepreneurial universities, while in Bulgaria the most important facilitators are linked to important stakeholders such as business partners and current and potential students. These results do not coincide entirely with Kirby et al. (2011) who identify favourable staff attitudes toward entrepreneurship and links with industry as the most important facilitators.

This study provides evidence that significant barriers to the transformation are related not only to the internal environment but also to the external context, which supports previous research by Kirby et al. (2011). Similarly to Kirby et al. (2011), organizational structure and governance is ranked as the most important barrier to becoming more entrepreneurial in Bulgaria and the second most important barrier in 
Portugal after mindset/ mentality of the academic and administrative staff. It should be noted that the lack of appropriate legislation is seen as the second most important barrier in Bulgaria, which is not surprising as there is an absence of long-term national policy framework that guides and supports innovation and entrepreneurship in Bulgaria (OECD, 2014). An important finding of this study is the observation that the relative importance of the various internal and external factors is context specific. The most frequently mentioned barriers and facilitators are different between the research contexts in the current study (Bulgaria and Portugal) as well as in relation to the findings in Kirby's et al. (2011) study.

These results have practical implications for universities and policy makers. Rectors, deans and heads of departments must be aware of the internal challenges to making their universities more entrepreneurial as well as of factors that may facilitate the process of transformation. Specific attention should be focused on strengthening entrepreneurship ecosystem and building adequate entrepreneurship support infrastructure within Bulgarian and Portuguese universities. Policy makers should devote special attention to external barriers to the transformation and especially to the need for more appropriate legal framework and more state funding. State finding may be partially bound with the requirements for technology transfer, patents, development of new products and services, number of spin-off companies, etc.

Following various European Commission initiatives supporting the links between higher education and business (Tache et al., 2017) may enhance the entrepreneurial orientation of universities. As public provision of education is important at regional and local level (Coelho and Oliveira, 2011), policy makers, local authorities and university administrators should implement specific policies and measure to stimulate the entrepreneurial transformation of regional universities. Future research should provide guidelines how to overcome specific barriers to the transformation of Bulgarian and Portuguese into entrepreneurial universities.

\section{References:}

Aldridge, T.T., Audretsch, D. 2011. The Bayh-Dole act and scientist entrepreneurship. Research policy, 40(8), 1058-1067.

Audretsch, D.B. 2009. The entrepreneurial society. The Journal of Technology Transfer, 34(3), 245-254.

Barnett, R. 2005. Convergence in Higher Education: The Strange Case of "Entrepreneurialism". Higher Education Management and Policy, 17(3), 51.

Clark, B.R. 1998. Creating Entrepreneurial Universities. Oxford: Pergamon.

Clarysse, B., Tartari, V., Salter, A. 2011. The impact of entrepreneurial capacity, experience and organizational support on academic entrepreneurship. Research policy, 40(8), 1084-1093.

Coelho, M.P., Oliveira, M.L. 2011. Externalities and public provision of education. International Journal of Latest Trends in Finance and Economic Sciences, 1(3), 142148. 
Etzkowitz, H. 1983. Entrepreneurial Scientists and Entrepreneurial Universities in American Academic Science. Minerva, 21(2-3), 198-233.

Etzkowitz, H. 2003. Research groups as 'quasi firms': the invention of the entrepreneurial university. Research Policy, 32, 109-121.

Etzkowitz, H. 2004. The evolution of the entrepreneurial university. International Journal of Technology and Globalisation, 1(1), 64-77.

Etzkowitz, H., Webster, A., Gebhardt, C., Terra, B.R.C. 2000. The future of the university and the university of the future: evolution of ivory tower to entrepreneurial paradigm. Research policy, 29(2), 313-330.

Fini, R., Grimaldi, R., Santoni, S., Sobrero, M. 2011. Complements or substitutes? The role of universities and local context in supporting the creation of academic spin-offs. Research Policy, 40(8), 1113-1127.

Fuller, S. 2005. What makes universities unique? Updating the ideal for an entrepreneurial age. Higher Education Management and Policy, 17(3), 27.

Gerry, C., Marques, C.S., Nogueira, F. 2008. Tracking student entrepreneurial potential: personal attributes and the propensity for business start-ups after graduation in a Portuguese university. Problems and Perspectives in Management, 6(4), 45-53.

Gibb, A.A., Haskins, G. \& Robertson. 2009. Leading the entrepreneurial university. National Council for Graduate Entrepreneurship (NCGE).

Gras, J.M.G., Lapera, D.R.G., Solves, I.M., Jover, A.J.V., Azuar, J.S. 2008. An empirical approach to the organisational determinants of spin-off creation in European universities. International Entrepreneurship and Management Journal, 4(2), 187-198.

Guenther, J., Wagner, K. 2008. Getting out of the ivory tower-new perspectives on the entrepreneurial university. European Journal of International Management, 2(4), 400417.

Guerrero, M. 2007. Entrepreneurial Universities: The Case of Autonomous University of Barcelona. Research Work, Universitat Autònoma de Barcelona. Barcelona.

Guerrero, M., Toledano, N., Urbano, D. 2011. Entrepreneurial universities and support mechanisms: a Spanish case study. International Journal of Entrepreneurship and Innovation Management, 13(2), 144-160.

Guerrero, M., Urbano, D., Cunningham, J., Organ, D. 2014. Entrepreneurial universities in two European regions: A case study comparison. The journal of technology Transfer, 39(3), 415-434.

Guerrero-Cano, M., Kirby, D., Urbano, D. 2006. A literature review on entrepreneurial universities: An institutional approach. In 3rd Conference of Pre-communications to Congresses, University of Barcelona.

Hu, M.C. 2009. Developing entrepreneurial universities in Taiwan: the effects of research funding sources. Science, Technology and Society, 14(1), 35-57.

Ibarra-Colado, E. 2007. Future university in present times: Autonomy, governance and the entrepreneurial university. Management revue, 18(2), 117-137.

Jacob, M., Lundqvist, M., Hellsmark, H. 2003. Entrepreneurial transformations in the Swedish University system: the case of Chalmers University of Technology. Research Policy, 32(9), 1555-1569.

Kerr, C. 1963.The uses of the University. London, England: Harvard University Press.

Kirby, D.A., Guerrero, M., Urbano, D. 2011. Making universities more entrepreneurial: Development of a model. Canadian Journal of Administrative Sciences/Revue Canadienne des Sciences de l'Administration, 28(3), 302-316.

Kirby, D.A. 2006. Creating Entrepreneurial Universities in the UK: Applying entrepreneurship theory to practice. The Journal of Technology Transfer, 31, 599-603. 
Lehrer, M., Nell, P., Gärber, L. 2009. A national systems view of university etrepreneurialism: Inferences from comparison of the German and US experience. Research Policy, 38(2), 268-280.

Markuerkiaga, L., Errasti, N., Igartua, J.I. 2014. Success factors for managing an entrepreneurial university: Developing an integrative framework. Industry and Higher Education, 28(4), 233-244.

Nelles, J. \& Vorley, T. 2010. Constructing an entrepreneurial architecture: An emergent framework for studying the contemporary university beyond the entrepreneurial turn. Innovative Higher Education, 35(3), 161-176.

OECD. 2014. Innovate Reviews: Universities, Entrepreneurship and Local Development. Promoting Innovation and Entrepreneurial Mind-Sets Through Higher Education. Country-Level Review Bulgaria, Available at: https://www.oecd.org/cfe/leed/OECDLEED-2015-Bulgaria-report.pdf.

Pawłowski, K. 2001. Towards the entrepreneurial university. Higher Education in Europe, 26(3), 427-436.

Philpott, K., Dooley, L., O'Reilly, C. \& Lupton, G. 2011. The entrepreneurial university: Examining the underlying academic tensions. Technovation, 31(4), 161-170.

Powers, J.B. \& McDougall, P.P. 2005. University start-up formation and technology licensing with firms that go public: a resource-based view of academic entrepreneurship. Journal of business venturing, 20(3), 291-311.

Rinne, R. \& Koivula, J. 2005. The changing place of the university and a clash of values the entrepreneurial university in the European knowledge society a review of the literature. Higher Education Management and Policy, 17(3), 91.

Röpke, J. 1998. The Entrepreneurial University, Innovation, academic knowledge creation and regional development in a globalized economy. Working Paper Department of Economics, Philipps-Universität Marburg, Germany, 15.

Rothaermel, FT., Agung, S.D., Jiang, L. 2007. University Entrepreneurship: taxonomy of the literature. Industrial and Corporate Change, 16(4), 691-791.

Sá, E., Dias, D., Sá, M.J. 2018. Towards the university entrepreneurial mission: Portuguese academics' self-perspective of their role in knowledge transfer. Journal of Further and Higher Education, 42(6), 784-796.

Salamzadeh, A., Salamzadeh, Y., Daraei, M. 2011. Toward a systematic framework for an entrepreneurial university: a study in Iranian context with an IPOO model. Global Business and Management Research: An International Journal, 3(1), 31-37.

Santiago, R., Carvalho, T., Relva, R. 2008. Research and the Universities' Image. European Journal of Education, 43(4), 495-512.

Smith, P.C., Vozikis, S.G., Merikas, A. 2000. Privatization, Management Education and Entrepreneurship: The Sine Qua Non Conditions for Economic Development in Eastern Europe. European Research Studies Journal, 3(1-2), 67-78.

Sporn, B. 2001. Building adaptive universities: Emerging organisational forms based on experiences of European and US universities. Tertiary Education \& Management, $7(2), 121-134$.

Subotzky, G. 1999. Alternatives to the Entrepreneurial University: New Modes of Knowledge Production in Community Service Programs. Higher Education, 38(4), 401-440.

Subotzky, G. 1999. Alternatives to the entrepreneurial university: New modes of knowledge production in community service programs. Higher education, 38(4), 401-440.

Tache, I., Bratucu, G., Chitu, I.B., Dovleac, L. 2017. Improving the relationship between higher education institutions and business environment in South-Eastern Europe: a 
case study. International Journal of Economics and Business Administration, 5(2), 313.

Van Looy, B., Landoni, P., Callaert, J., Van Pottelsberghe, B., Sapsalis, E., Debackere, K. 2011. Entrepreneurial effectiveness of European universities: An empirical assessment of antecedents and trade-offs. Research Policy, 40(4), 553-564.

Yusof, M. \& Jain, K.K. 2010. Categories of university-level entrepreneurship: a literature survey. International Entrepreneurship and Management Journal, 6(1), 81-96.

Zhou, C., and Peng, X. 2008. The entrepreneurial university in China: nonlinear paths. Science and Public Policy, 35(9), 637-646. 